\title{
Knowledge of Zika virus disease among reproductive-age women attending a general outpatient clinic in Northern Nigeria
}

\author{
GC Michaela* iD, I Aliyub iD, BA Grema $^{\mathrm{a}}$ and AO Ashimic \\ ${ }^{a}$ Department of Family Medicine, Aminu Kano Teaching Hospital, Kano, Nigeria \\ ${ }^{b}$ Department of Paediatrics, Aminu Kano Teaching Hospital, Kano, Nigeria \\ 'Department of Obstetrics and Gynaecology, Federal Medical Centre, Birnin Kudu, Nigeria \\ *Corresponding author, email: drgcmichael@gmail.com
}

Background: Nigeria is not insulated from the global threat of Zika virus disease (ZVD) because of international travel and the presence of Zika-virus-carrying mosquitoes in the country. A paucity of studies exists concerning knowledge of ZVD among atrisk populations. Thus, the necessity for assessment of knowledge of ZVD among reproductive-age women in general outpatient setting.

Materials and methods: A cross-sectional study was conducted on 377 reproductive-age women attending a Nigerian tertiary hospital's general outpatient clinic. Their knowledge of ZVD was assessed using a structured questionnaire. A chi-square test was used to assess the relationship between participants' sociodemographics and ZVD knowledge.

Results: The participants' median age was $27.0 \pm 7.19$ years. Though $68.97 \%$ of participants were aware of ZVD, only $23.85 \%$ of those had good knowledge of ZVD. Their median knowledge score was $57.14 \%$. Participants' age $(<27$ years $)(p=0.00399)$, tribe (Hausa) $(p=0.0174)$ and monogamous family type $(p=0.0108)$ were associated with good knowledge of ZVD. Only $5 \%$ knew that ZVD is transmitted through both mosquito bites and a sexual route. Some $80 \%$ were unaware that everybody was at risk of ZVD but $80.77 \%$ knew it could cause microcephaly. Insecticide-treated nets (80.77\%), environmental sanitation (78.08\%) and indoor insecticide spraying $(58.85 \%)$ were preventive measures reported by most participants; a minority reported mosquito repellents $(28.46 \%)$, wearing of protective clothing $(36.15 \%)$, and traditional medicines $(20.00 \%)$ as preventive measures. They lacked knowledge of prevention of sexual transmission.

Conclusion: Participants' knowledge of ZVD was inadequate despite the high awareness rate. Stakeholders may need to address existing knowledge gaps through effective public enlightenment.

Keywords: knowledge, Nigeria, outpatients, reproductive-age women, Zika virus

\section{Introduction}

Zika virus disease (ZVD) was previously regarded as a mild disease but became a global public health emergency when strong associations were reported between the disease and microcephaly, foetal deaths and serious neurological disorders, particularly Guillain-Barré syndrome in the Americas. ${ }^{1}$ Additionally, over 53 countries (including African countries such as Cape Verde and Guinea-Bissau) have had their first reported outbreak of mosquito-borne Zika virus transmission since $2015 .{ }^{2}$

The virus was first identified in rhesus monkeys in the forest of Zika near Entebbe, Uganda in 1947. However, outbreaks of ZVD in humans have been recorded in other parts of Africa, the Americas, Asia and the Pacific. ${ }^{3}$ In Nigeria, human infection by Zika virus (a flavirus) was reported by Macnamara et al. in 1954 in Afikpo, eastern Nigeria while investigating an outbreak of jaundice; since then there have been no reports concerning the disease. ${ }^{4}$

ZVD is primarily transmitted through the bite of infected Aedes mosquitoes (Aedes aegypti). ${ }^{5}$ However, sexual transmission has also been reported in the USA. ${ }^{6}$ The Aedes mosquito typically bites humans during the morning and late afternoon/evening hours. It hardly flies distances of more than $\mathbf{4 0 0}$ metres, but can be accidentally transported from place to place. ${ }^{7}$ It also transmits yellow fever, chikungunya fever and dengue fever viruses. ${ }^{8}$ The Aedes mosquito is a common mosquito species in most regions of Nigeria and West Africa with reports of Aedes mosquito-borne Zika virus transmission in Cape Verde and Guinea-Bissau. 2, 9-11
In about $80 \%$ of cases ZVD is asymptomatic; symptomatic disease is characterised by non-specific symptoms, making diagnosis difficult. ${ }^{8}$ Though there is no diagnosed case of ZVD in Nigeria, experts fear that the disease may have occurred in Nigeria' ${ }^{12}$ as microcephalic babies (with an extrapolated incidence of $1810 / 125750356$ live births) $)^{13}$ are seen from time to time in our hospitals and commonly managed as congenital microcephaly ${ }^{14}$ without probing and establishing the exact cause. Furthermore, globalisation and international travel make exposure of Nigerians to individuals who reside or have travelled to areas of active Zika virus transmission inevitable.

There is currently no specific treatment or vaccine for ZVD. The best form of prevention currently is protection against mosquito bites and appropriate strategies to prevent non-mosquito-borne transmission. ${ }^{8}$ However, some of the preventive strategies in women of reproductive age are similar to those of malaria prevention, for instance sleeping under an insecticide-treated net, one of the benefits of focused antenatal care.

To our knowledge, there has been no study on the knowledge of ZVD among reproductive age women in northern Nigeria. Knowledge of a disease has the potential to influence behaviour change towards prevention. ${ }^{15}$ This study was therefore undertaken to assess the knowledge of ZVD among these women and to create ZVD awareness among clinicians and the general public. It may also be useful to policy-makers in developing strategies for preventing ZVD and could serve as a basis for conducting future studies. 


\section{Materials and methods}

A descriptive cross-sectional study was conducted on females of reproductive age who were accessing primary care services at the general outpatient clinic of Aminu Kano Teaching Hospital (AKTH) Kano, northwest Nigeria from September 1 to 28, 2016. Of a weekly average of 1350 patients seen at the clinic (from clinic records), $60 \%$ (810) are women of reproductive age. Therefore, the sampling frame was $3240(810 \times 4)$ for the fourweek study period.

A systematic random sampling technique was used to select 377 participants; sample size was obtained using the formula [n/ $(1+n / N)]$ for calculating sample size less than 10000 and an empirical knowledge prevalence of $50 \%$. The first participant was selected by balloting; thereafter every 8th (3240/377) woman of reproductive age was recruited until the sample size was obtained. All women of reproductive age (15 to 44 years) ${ }^{16}$ who accessed care at the clinic during the study period were included in the study. However, women with emergency conditions or who declined consent were excluded. Written informed consent was obtained from each participant after explaining the study objectives. Ethical approval was obtained from the AKTH Research Ethics Committee.

The investigator and two female research assistants trained in questionnaire administration technique administered a developed, structured and pretested questionnaire in English or in the Hausa language to each participant. The questionnaire was initially in English, but was translated into Hausa (the local language) and back-translated into English by two linguistic professionals and two physicians to check for consistency and semantic validity. Their sociodemographic characteristics (section one) and awareness of ZVD, knowledge of reported complications of ZVD, and preventive measures (section two) were assessed. Knowledge of ZVD was assessed using closedended questions with 'yes' and 'no' responses, e.g. Have you heard of Zika virus disease before? Yes/No; From which source did you first hear it? Radio (Yes/No), TV (Yes/No), Newspaper (Yes/No), School (Yes/No), Internet (Yes/No), Family and Friends (Yes/No), I don't know. The knowledge score was derived from the sum of all the correct answers from section two of the questionnaire divided by 21 (the total number of question items); the quotient was then multiplied by 100 . Scores of $0-49.9$, 50.0-69.9 and 70-100 percent were considered poor, average and good knowledge of ZVD respectively. Inadequate knowledge of ZVD was defined as scores of 0-69.9 (i.e. poor and average knowledge).

Data were entered using Epi Info ${ }^{\circledR}$ Version 7.1.1.14 (CDC, Atlanta GA, USA, 2012). Categorical variables were described in percentages whereas quantitative variables were described using proportions and measures of central tendencies and dispersion. The chi-square test was used to determine the association between sociodemographic variables and knowledge of ZVD. Statistical significance was set at a $p$-value of less than 0.05 .

\section{Results}

\section{Sociodemographic characteristics}

Of the 377 participants recruited for the study, all completed the questionnaire with a respondent rate of $100 \%$. Their median age was $27.0 \pm 7.19$ (SD) years. In all, 182 (48.28\%) participants had tertiary education and a majority were from the Hausa tribe
Table 1: Participants' sociodemographic characteristics

\begin{tabular}{|c|c|c|}
\hline Characteristics & Frequency & Percentage \\
\hline \multicolumn{3}{|l|}{ Age } \\
\hline $15-24$ & 140 & 37.13 \\
\hline $25-34$ & 156 & 41.38 \\
\hline $35-44$ & 81 & 21.49 \\
\hline \multicolumn{3}{|l|}{ Educational level } \\
\hline None & 14 & 3.71 \\
\hline Quranic & 36 & 9.55 \\
\hline Primary & 28 & 7.43 \\
\hline Secondary & 117 & 31.03 \\
\hline Tertiary & 182 & 48.28 \\
\hline \multicolumn{3}{|l|}{ Tribe } \\
\hline Hausa & 195 & 51.72 \\
\hline Fulani & 92 & 24.40 \\
\hline Yoruba & 33 & 8.75 \\
\hline Ebira & 20 & 5.31 \\
\hline Others* & 37 & 9.82 \\
\hline \multicolumn{3}{|l|}{ Occupation } \\
\hline Unemployed & 169 & 44.83 \\
\hline Civil servant & 88 & 23.34 \\
\hline Trading & 70 & 18.57 \\
\hline Students/interns & 36 & 9.55 \\
\hline Others ${ }^{* *}$ & 14 & 3.71 \\
\hline \multicolumn{3}{|l|}{ Marital status } \\
\hline Married & 239 & 63.56 \\
\hline Single & 101 & 26.86 \\
\hline Divorced & 11 & 2.93 \\
\hline Widowed & 25 & 6.65 \\
\hline \multicolumn{3}{|c|}{ Reported pregnancy status } \\
\hline Pregnant & 75 & 19.89 \\
\hline Not pregnant & 302 & 80.11 \\
\hline \multicolumn{3}{|l|}{ Family type } \\
\hline Monogamy & 236 & 62.60 \\
\hline Polygamy & 141 & 37.40 \\
\hline \multicolumn{3}{|l|}{ Number of children } \\
\hline $0-4$ & 294 & 77.98 \\
\hline $5-12$ & 83 & 22.02 \\
\hline
\end{tabular}

*Igbo (18, 4.77\%), Kanuri (11, 2.92\%), Igala (4, 1.06\%), Nupe $(2,0.53 \%)$, Auchi $(1,0.27 \%)$, Idoma (1, 0.27\%).

**Tailors $(8,2.12 \%)$, company workers $(2,0.53 \%)$, hairdressing/weaving $(2,0.53 \%)$, lawyer $(1,0.27 \%)$, farmer $(1,0.27 \%)$.

(51.72\%) (Table 1). A preponderance of the participants were married $(63.56 \%)$, and were from monogamous family settings (62.60\%). A majority were not gainfully employed (44.83\%). The participants had a median of $2.0 \pm 2.52$ children ranging from 0 to 12 children. Seventy-five (19.89\%) of them reported that they were pregnant.

\section{Participants' knowledge of ZVD and its reported} complications

A majority of the participants 260 (68.97\%) have heard of ZVD (Table 2); this information was mainly obtained from listening to 
Table 2: Participants' knowledge of ZVD and its reported complications $(\boldsymbol{n}=260)$

\begin{tabular}{|c|c|c|}
\hline Variables & Frequency & Percentage \\
\hline \multicolumn{3}{|l|}{ Have you heard of ZVD? } \\
\hline Yes & 260 & 68.97 \\
\hline No & 117 & 31.03 \\
\hline \multicolumn{3}{|l|}{ Information source } \\
\hline Radio & 124 & 47.69 \\
\hline Hospital & 58 & 22.31 \\
\hline Television & 29 & 11.15 \\
\hline Internet & 18 & 6.92 \\
\hline Family and friends & 17 & 6.54 \\
\hline Newspaper & 10 & 3.85 \\
\hline School & 4 & 1.54 \\
\hline \multicolumn{3}{|l|}{ Transmission through } \\
\hline Mosquito bite only & 174 & 66.92 \\
\hline Mosquito bite and sexual route & 13 & 5.00 \\
\hline From rats & 12 & 4.62 \\
\hline Drinking bad water & 7 & 2.69 \\
\hline Bad air & 6 & 2.31 \\
\hline I don't know & 48 & 18.46 \\
\hline \multicolumn{3}{|l|}{ Can ZVD kill? } \\
\hline Yes & 150 & 57.69 \\
\hline No & 99 & 38.08 \\
\hline I don't know & 11 & 4.23 \\
\hline \multicolumn{3}{|l|}{ Can ZVD affect everybody? } \\
\hline Yes & 52 & 20.00 \\
\hline No & 98 & 37.69 \\
\hline I don't know & 110 & 42.31 \\
\hline \multicolumn{3}{|c|}{ What is the effect of ZVD on the unborn/newborn child? } \\
\hline \multicolumn{3}{|l|}{ Small head } \\
\hline Yes & 210 & 80.77 \\
\hline No & 50 & 19.23 \\
\hline \multicolumn{3}{|l|}{ Brain damage } \\
\hline Yes & 171 & 65.77 \\
\hline No & 89 & 34.23 \\
\hline \multicolumn{3}{|l|}{ I don't know } \\
\hline Yes & 16 & 6.15 \\
\hline No & 244 & 93.85 \\
\hline
\end{tabular}

the radio (47.69\%). Most of the participants (66.92\%) reported that ZVD was transmitted via mosquito bites. Only $5.0 \%$ reported that it was transmitted via both mosquito bites and sexual routes; $18.46 \%$ did not know how the disease is transmitted. Similarly, a slight majority reported that ZVD can kill (57.69\%). However, $80.77 \%$ knew that ZVD could cause a small head in newborns and $65.77 \%$ reported that it could cause nerve and brain damage. Remarkably, $80 \%$ of the participants either did not know if everybody was at risk of getting infected or reported that not everybody was at risk.

\section{Participants' knowledge of preventive measures}

A preponderance of participants (89.62\%) reported that ZVD was preventable (Table 3). Environmental sanitation, use of insecticide-treated nets and insecticide spraying were preventive
Table 3: Participants' knowledge of ZVD prevention $(\boldsymbol{n}=260)$

\begin{tabular}{|c|c|c|}
\hline Variables & Frequency & Percentage \\
\hline \multicolumn{3}{|c|}{ Do you think ZVD is preventable? } \\
\hline Yes & 233 & 89.62 \\
\hline No & 13 & 5.00 \\
\hline I don't know & 14 & 5.38 \\
\hline \multicolumn{3}{|c|}{ ZVD can be prevented via } \\
\hline \multicolumn{3}{|c|}{ Environmental sanitation } \\
\hline Yes & 203 & 78.08 \\
\hline No & 57 & 21.92 \\
\hline \multicolumn{3}{|c|}{ Insecticide-treated nets } \\
\hline Yes & 210 & 80.77 \\
\hline No & 50 & 19.23 \\
\hline \multicolumn{3}{|c|}{ Insecticide spraying } \\
\hline Yes & 153 & 58.85 \\
\hline No & 107 & 41.15 \\
\hline \multicolumn{3}{|c|}{ Use of mosquito repellents } \\
\hline Yes & 74 & 28.46 \\
\hline No & 186 & 71.54 \\
\hline \multicolumn{3}{|c|}{ Use of protective clothing in the day } \\
\hline Yes & 94 & 36.15 \\
\hline No & 166 & 63.85 \\
\hline \multicolumn{3}{|c|}{ Use of traditional medicine (herbs) } \\
\hline Yes & 52 & 20.00 \\
\hline No & 208 & 80.00 \\
\hline
\end{tabular}

measures reported by most of them. However, a minority reported that mosquito repellents (28.46\%), wearing of protective clothing (36.15\%) and use of traditional medicines (herbs) could be used to prevent ZVD transmission. Sixteen (6.15\%) participants did not know how the disease could be prevented. None knew of any preventive measure against sexual transmission.

\section{Participants' knowledge of ZVD}

A majority of the participants 133 (51.15\%) had average knowledge of ZVD. Sixty-five (25.0\%) and 62 (23.85\%) participants had poor and good knowledge of ZVD respectively (Figure 1). The median ZVD knowledge score of the participants was $57.14 \pm 13.69 \%$.

Relationship between participants' sociodemographic characteristics and knowledge of ZVD

A higher proportion of participants of age $<27$ years $(59.68 \%)$ had good knowledge of ZVD when compared with those $\geq 27$ years of age and the difference in proportions was found to be statistically significant (chi-square $=9.812$, $p=0.00174$ ) (Table 4). Similarly, more participants of the Hausa tribe $(67.74 \%)$ had good knowledge of ZVD when compared with the non-Hausa participants and this difference in proportions was also statistically significant (chi-square $=5.660$, $p=0174)$. There was a higher proportion of participants from monogamous families (77.42\%) who had adequate knowledge of ZVD when compared with those from polygamous families; this difference in proportions was statistically significant (chisquare $=6.498, p=0.0108$ ). There were no statistical associations between participants' educational level, marital status, reported pregnancy status, number of children and knowledge of ZVD. 


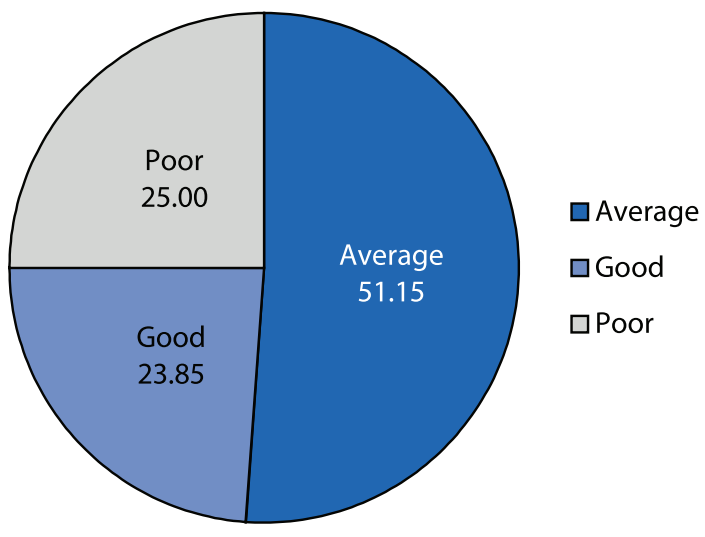

Figure 1: Participants' knowledge of ZVD.

Table 4: Relationship between participants' sociodemographic characteristics and knowledge of ZVD

\begin{tabular}{|c|c|c|c|}
\hline \multirow[t]{2}{*}{ Variable } & \multicolumn{2}{|c|}{ ZVD knowledge $n(\%)$} & \multirow[t]{2}{*}{ Statistics } \\
\hline & Good & Inadequate* & \\
\hline Age & & & $\chi^{2}=8.287$ \\
\hline$<27$ & $37(57.68)$ & 77 (38.89) & $d f=1$ \\
\hline$\geq 27$ & $25(40.32)$ & $121(61.11)$ & $p=0.00399^{*}$ \\
\hline Educational level & & & $\chi^{2}=1.837$ \\
\hline Lower** & $7(11.29)$ & 37 (18.69) & $\mathrm{df}=1$ \\
\hline Higher*** & $55(88.71)$ & $161(81.31)$ & $p=0.1752$ \\
\hline Tribe & & & $\chi^{2}=5.660$ \\
\hline Hausa & $42(67.74)$ & $100(50.51)$ & $d f=1$ \\
\hline Non-Hausa & $20(32.26)$ & 98 (49.49) & $p=0.0174^{*}$ \\
\hline Occupation & & & $\chi^{2}=3.679$ \\
\hline Unemployed & $29(46.77)$ & $66(33.33)$ & $d f=1$ \\
\hline $\begin{array}{l}\text { Employed/ } \\
\text { students }\end{array}$ & $33(53.23)$ & $132(66.67)$ & $p=0.0551$ \\
\hline Marital status & & & $\chi^{2}=0.466$ \\
\hline Married & $37(59.68)$ & $127(64.47)$ & $\mathrm{df}=1$ \\
\hline Others & $25(40.32)$ & $70(35.53)$ & $p=0.4949$ \\
\hline $\begin{array}{l}\text { Reported pregnancy } \\
\text { status }\end{array}$ & & & $\chi^{2}=230$ \\
\hline Pregnant & $12(19.35)$ & $44(22.22)$ & $\mathrm{df}=1$ \\
\hline Non-pregnant & $50(80.65)$ & $154(77.78)$ & $p=0.6317$ \\
\hline Family type & & & $\chi^{2}=6.498$ \\
\hline Monogamy & $48(77.42)$ & $118(59.60)$ & $d f=1$ \\
\hline Polygamy & $14(22.58)$ & $80(40.40)$ & $p=0.0108^{*}$ \\
\hline Number of children & & & $\chi^{2}=0.694$ \\
\hline$\leq 4$ & $51(82.26)$ & $153(77.27)$ & $d f=1$ \\
\hline$>4$ & $11(17.74)$ & 45 (22.73) & $p=0.4047$ \\
\hline
\end{tabular}

*Inadequate: poor and average knowledge.

**Lower: none, Quranic and primary education.

***Higher: secondary and tertiary education.

\section{Discussion}

Zika virus disease remains a global threat, especially in developing countries with insufficient support systems for epidemics as was witnessed in the Ebola virus epidemic in West Africa. While there is incomplete knowledge of how the Zika virus affects the human body and its treatment, the World Health
Organization has provided recommendations on the primary prevention of this mosquito-borne and sexually transmitted disease. We therefore explored the knowledge of ZVD among reproductive-age women at an outpatient clinic in northern Nigeria.

We found a high literacy level among the study participants with about $80 \%$ of them having at least secondary school education. This could be responsible for the high disease awareness rate of $69 \%$ found in this study. However, educational level was not statistically associated with knowledge of ZVD $(p=0.175)$. Furthermore, there was an association between participants' age $(<27$ years) and good knowledge of ZVD ( $p=0.00174)$. This observation could also be a result of the high literacy level of the participants, as most students will belong to this age group. This age group could be a target for intervention programmes as they are more likely to accept information concerning ZVD. The associations between participants from the Hausa tribe, those from monogamous families and good knowledge of ZVD was an observation that we suspect could have resulted from a combination of participant variables, some of which may not have been studied; the reasons for this association could be a subject for future studies.

The mass media are an important source of health information for the empowerment of individuals and communities to make important health decisions in Nigeria. ${ }^{17}$ A majority of the study participants obtained information about ZVD from listening to the radio. This supports reports by Anatsui, who opined that radio has the ability to reach the remotest parts of the country because usage is not totally dependent on electricity supply like television sets. ${ }^{18}$ Recent advances in technology and communication and the widespread use of smart mobile phones in Nigeria have resulted in improved access to health information by the populace. These smartphones can access the internet, online newspapers and even the radio to gain health information. ${ }^{19}$ However, only $6 \%$ of our study participants acquired information through the internet and the study did not assess the ownership and use of smartphones among participants. Additionally, some of our study participants heard about ZVD via reading newspapers, watching television, at school (for students), hospital staff (during health talks) and from family and friends, suggesting that these are also important sources of and opportunities for the dissemination of health information.

The Zika virus has also been reported to be present in amniotic fluid, ${ }^{20}$ urine, ${ }^{21}$ saliva, ${ }^{22}$ breast milk ${ }^{23}$ and semen ${ }^{24,25}$ of infected individuals, thereby making transmission via other routes possible. However, we observed that only $5 \%$ of the study participants knew that ZVD could be transmitted through mosquito bites as well as sexual intercourse with infected persons. Furthermore, $9 \%$ of the participants wrongly cited drinking bad water, inhaling bad air and transmission from rats as ways of transmitting the disease while $18 \%$ did not know how the disease is transmitted. Some $70 \%$ of the participants knew about the mosquito-borne transmission route only. These observations suggest a disparity between the proportion of participants' aware of the disease and the proportion that knew the routes of transmission. This disparity could be due to multiple factors including the inadequate knowledge of ZVD by participants that was found by this study. In total, $76 \%$ of the study participants had inadequate knowledge (poor and average knowledge) of the disease. Other factors could be ineffective radio enlightenment programmes among others. However, 
erroneous beliefs and lack of knowledge of ZVD transmission has the potential to impact negatively on control efforts as energy and resources will be wrongly channelled by such individuals.

The Aedes mosquito is a common mosquito species in many parts of Nigeria; its larvae inhabit stagnant pools, gutters, containers and automobile tyres and often coexist with those of anopheline mosquitoes that transmit malaria. ${ }^{9-11}$ Environmental sanitation, sleeping under insecticide-treated bed nets and indoor insecticide spraying are proven ways of preventing the bite of mosquitoes. ${ }^{8}$ The use of mosquito repellents in the form of creams or lotions and wearing of long shirts and trouser will aid in preventing outdoor Aedes mosquitoes bite during the morning and late afternoon/evening hours when most people are still outdoors. ${ }^{8}$ In our study a majority of the participants knew that environmental sanitation (clearing of bushes, stagnant gutters, etc.), insecticide-treated nets and indoor insecticide were useful ways of preventing ZVD and this has the potential to impact positively on individuals' prevention efforts. However, only a minority knew it could be prevented using mosquito repellents and wearing protective clothing. This can potentially affect prevention among these individuals. A few reported the use of unproven traditional medicines (herbs) as preventive measures; this may result in these individuals misdirecting their efforts towards ineffective preventive measures. Additionally, $6 \%$ of the women did not know any preventive measures for ZVD. This proportion will become a significant group when extrapolated to the community and has importance for public health.

Until new information emerges, the World Health Organization recommends that in regions with no active Zika virus transmission (such as Nigeria) health programmes should ensure that men and women returning from areas of active Zika virus transmission should adopt safer sex practices (use condoms) or consider abstinence for at least eight weeks upon return while men with ZVD should wait for six months after symptom onset to attempt conception. ${ }^{26}$ In our study, only 5\% knew about sexual transmission of the disease. This is worrisome because women of reproductive age are at risk of infection as they could be infected during sexual intercourse. This route of transmission has been reported in the USA. ${ }^{6}$

ZVD has been associated with foetal death, microcephaly and severe neurological disorders like Guillain-Barré syndrome. ${ }^{1}$ Surprisingly, only about half of our study participants knew that ZVD could be fatal. Similarly, a majority did not know that the disease could affect everybody in the community. This has the potential to affect their health-seeking behaviour and the demand for health education for prevention. However, a majority knew that the disease potentially causes the delivery of babies with small heads and nerve/brain damage

\section{Policy implications}

This study highlights the need for further effective public enlightenment programmes to address the existing knowledge gaps regarding ZVD, especially primary prevention, to avert a future epidemic in the country as witnessed in the Americas. Similarly, women of reproductive age should be targeted for any intervention efforts as the proportion of women with good knowledge of ZVD in this study was low. The Nigerian government may need to be proactive in articulating deliberate policy towards preventing the disease to avert avoidable mortality.

\section{Limitation of the study}

Lack of local studies in this domain has made comparison of results difficult. Similarly, being a cross-sectional study it was difficult to infer causality between study variables and it may be difficult to extrapolate study outcome to the community because most women attending the hospital belong to the middle and high social class. In addition, this hospital is situated in the urban part of Kano. Similarly, the use of closed-ended questions in the questionnaire could result in some participants guessing the correct answers, leading to spurious interpretations.

\section{Future research}

Future studies may need to explore ZVD knowledge among couples (husband and wife/wives) and the general public using the appropriate tools.

\section{Conclusion}

Though the awareness rate of ZVD was above average, knowledge of the disease was low among participants. Deliberate efforts by all stakeholders (all levels of government inclusive) may be required for policy towards prevention of the disease through effective public enlightenment programmes. These programmes may need to target populations such as women of reproductive age, whose action or inaction could result in an increase in the number of foetal deaths and neurological disorders associated with the disease.

Conflict of interest - The authors declare that they have no financial or personal relationship(s) which may have inappropriately influenced the writing of this paper.

Acknowledgement - The authors would like to acknowledge the invaluable contribution of the research assistants Zubaida Khaleel and Aisha Mohammed for their time and commitment in administration of the questionnaires.

\section{ORCID}

GC Michael (D) http://orcid.org/0000-0003-4008-4483

I Aliyu (D) http://orcid.org/0000-0003-0018-1828

\section{References}

1. WHO. WHO statement on the first meeting of the International Health Regulations (2005) (IHR 2005). Emergency Committee on Zika virus and observed increase in neurological disorders and neonatal malformations. [Cited 2016 Feb 21]. Available from: http://www.who. int/mediacentre/news/statements/2016/1st-emergencycommitteeZika/en/\#

2. World Health Organization. Zika situation report (data of 17 August 2016). [Cited 2016 Sep 22]. Available from: http://www.who.int/ emergencies/Zika-virus/situation-report/18-august-20

3. Weinberg MP, Williams MC. Zika virus: Further Isolations in the Zika Area and some studies on the strain isolated. Trans Royal Soc Trop Med Hyg. 1958;52(3):263-8.

4. Macnamara FN. Zika virus: A report on three cases of human infection during an epidemic of jaundice in Nigeria. Trans Royal Soc Trop Med Hyg. 1958;49(2):139-45.

5. Dick GWA. Zika virus (II). pathogenicity and physical properties. Trans Royal Soc Trop Med Hyg. 1952;46:521-34. https://doi. org/10.1016/0035-9203(52)90043-6

6. Dallas County Health and Human Services. DCHHS reports first Zika virus case in Dallas County acquired through sexual transmission. 2016 Feb 2 [Cited 2016 Sep 23]. Available from: http://www. dallascounty.org/department/hhs/press/documents/PR2-2-

7. Joseph AO, Adepeju SOI, Omosalewa OB. Distribution, abundance and diversity of mosquitoes in Akure, Ondo State, Nigeria. J Parasit Vector Biol. 2013;5(10):132-6. 
8. WHO. Zika Virus Fact Sheet. [Cited 2016 Sep 6]. Available from: www. who.int/mediacentre/factsheet/Zika/en

9. Adebote DA, Oniye SJ, Ndams IS, et al. The breeding of mosquitoes (Diptera: Culicidae) in peridomestic containers and implications in yellow fever transmission in villages around Zaria, Northern Nigeria. J Entomo. 2006;3(2):180-8.

10. Odo GE, Agwu EJ, Haruna AS. Culicid forms distribution and breeding sites in Nsukka ecological zone of south eatern Nigeria. J Parasit Vector Biol. 2015;7(5):94-100.

11. Okogun GRA, Anosike JC, Okere AN, et al. Ecology of mosquitoes of Midwestern Nigeria. J Vector Borne Dis. 2005;42:1-8.

12. Bukola Adebayo. Doctors fear Zika might have occurred in Nigeria. Punch Newspaper (online). 2016 Feb 10 [Cited 2016 Sep 23]. Available from: http://punchng.com/doctors-fear-Zika-might-have-occurredin-nigeria/

13. Statistics by country for microcephaly. [Cited 2016 Nov 1]. Available from: http://www.rightdiagnosis.com/m/microcephaly/stats-country.htm

14. Olusanya BO. Full-term newborns with congenital microcephaly and macrocephaly in Southwest Nigeria. International Health 2012;4(2):128-34. https://doi.org/10.1016/j.inhe.2011.12.006

15. HuntDP. The concept of knowledge and how to measureit. Intellectual Capital 2003;4(1):100-13.https://doi.org/10.1108/14691930310455414

16. World Health Organization: Women's health. Fact sheet. [Cited 2016 Mar 9]. Available from: http://www.who.int/mediacentre/factsheet/ fs334/en/

17. Anyaoku EN. Empowering patients for chronic disease selfmanagement through access to health information in Nigeria: overview of strategies. J Health inf. 2014;2(1):22-8.

18. Anatsui TC. Communicating health information at grassroots in Nigeria. JORIND 2014;12(1). ISSN 1596-8308. [Cited 2016 Oct 4]. Available from: http://www.transcampus.org/journal; www.ajol.info/ journals/jorind
19. Ana P, Obidinnu JN. Exploratory review towards the adaptation of trending mobile phone based health information dissemination in Nigeria. Online J Phys Environ Sci Res. 2013;2(3):38-42. ISSN 23155027.

20. Brasil P, Pereira JP Jr, Gabaglia CR, et al. Zika virus infection in pregnant women in Rio de Janeiro - preliminary report. N Engl J Med 2016 Mar:1-11. doi:10.1056/NEJMoa1602412.

21. Fonseca K, Meatherall B, Zarra D, et al. First case of Zika virus infection in a returning canadian traveler. Am J Trop Med Hyg 2014;91:1035-8. https://doi.org/10.4269/ajtmh.14-0151

22. Musso D, Roche C, Nhan TX, et al. Detection of Zika virus in saliva. J Clin Virol 2015;68:53-5. https://doi.org/10.1016/j.jcv.2015.04.021

23. Dupont-Rouzeyrol M, Biron A, O'Connor O, et al. Infectious Zika viral particles in breastmilk. Lancet 2016;387:1051. https://doi. org/10.1016/S0140-6736(16)00624-3

24. Musso $D$, Roche $C$, Robin $E$, et al. Potential sexual transmission of Zika virus. Emerg Infect Dis 2015;21:359-61. https://doi.org/10.3201/ eid2102.141363

25. Mansuy JM, Dutertre $M$, Mengelle $C$, et al. Zika virus: high infectious viral load in semen, a new sexually transmitted pathogen? Lancet Infect Dis 2016;16:405. https://doi.org/10.1016/S14733099(16)00138-9

26. World Health Organization: Prevention of sexual transmission of Zika virus. Interim guidance update 6 September 2016. [Cited 2016 Sep 23]. Available from: http://reliefweb.int/report/world/preventionsexual-transmission-Zika-virus-interim-guidance-update-6september-2016

Received: 04-11-2016 Accepted: 25-03-2017 